\title{
How Well Establishment of Research Plans Can Improve Scientific Ranking of Medical Universities
}

\author{
Seyed Hassan Saadat ${ }^{1}$; Morteza Izadi ${ }^{2}$; Jafar Aslani ${ }^{3}$; Mostafa Ghanei ${ }^{3,{ }^{*}}$ \\ ${ }_{1}^{1}$ Behavioral Science Research Center, Baqiyatallah University of Medical Sciences, Tehran, IR Iran \\ ${ }^{2}$ Health Research Center, Baqiyatallah University of Medical Sciences, Tehran, IR Iran \\ ${ }^{3}$ Research Center of Chemical Injuries, Baqiyatallah University of Medical Sciences, Tehran, IR Iran \\ *Corresponding Author: Mostafa Ghanei, Research Center of Chemical Injuries, Baqiyatallah University of Medical Sciences, Tehran, IR Iran. Tel: +98-9361046670, E-mail: mghanei@ \\ hbi.ir
}

Received: February 16, 2014; Revised: October 26, 2014; Accepted: November 12, 2014

\begin{abstract}
Background: As a developing country, Iran has not had a substantial share in global science production activities; however, this country has recently been the forth country in the world regarding research output publications, and biomedical research has played a crucial role in achieving this honorable position.

Objectives: In this paper, we aimed to introduce the strategies employed at Baqiyatallah University of Medical Sciences of Iran, to enhance scientific research output of this university.

Patients and Methods: The present study used the qualitative content analysis technique. The Research deputies and the head of research centers of Baqiyatallah University of Medical Sciences were the research subjects. The main researcher conducted all the interviews. The participants were all authorities of the university. Sampling continued until data saturation. After speaking with 16 participants, the interviews yielded no new information, and no new categories or subcategories were added to the previous ones. Deep and semistructured interviews with open-ended questions were used to collect data.

Results: Diplomacies employed to promote research, organizing educational classes, and foundation of infrastructural organizations for research and true surveillance of research programs were the main characteristics of Baqiyatallah University of Medical Sciences research strategies.

Conclusions: Baqiyatallah University of Medical Sciences is a military university of limited resources that has won several awards in the recent years, and has been categorized as one of the leading first ranked medical universities in Iran; a position quite higher than several other larger universities of the country. We recommend more enhanced strategies for other universities.
\end{abstract}

Keywords:Research; Education; Medical; Graduate; Science

\section{Background}

Biomedical research is an essential part of medical practice, not only due to its role in improving health care, but also due to its central role to progress medical sciences ( 1 , 2). Advances in disease surveillance, diagnosis, treatment and prevention all rely heavily on quality research, while this research also influences health care policy (3-5). In addition, scientific thinking skills of people are greatly improved because of their involvement in research endeavors. Physicians incorporate data from their research endeavors (6) into clinical practice to enhance their ability to manage their patients. Moreover, by being involved in research, clinicians' understanding of the critical importance of medical guidelines and dangers of malpractice is substantially improved.

During the past century (ies), the developing world has thoroughly relied on research findings and their interpretation provided by scientists of the developed world. However, as can be seen, this approach has not worked well, and it seems to be an unreliable solution to the problems of these countries. Apart from scientific retardation result- ing from the one-way use of other nations' scientific productions, one thing that might work very well in one country, might not be useful for another country with quite different circumstances. For example, funds used (e.g. by insurance agencies) to implement expensive procedures in the management of a rare disease with no definite treatment, in a developing country might be used for prevention of a critical health problem (e.g. AIDS) or to save several lives of patients who may need less foundation.

During the recent decades, however, some slow advances have been made in medical research by researchers from developing countries. As a developing country, Iran has not had a substantial share in global science production activities; nevertheless, this country has recently been the forth country in the world in research output publications, and biomedical research has played a crucial role in achieving this honorable position. Baqiyatallah University of Medical Sciences is a military university with relatively limited human and material resources compared to the universities of other countries; yet this university has become the fore-

Copyright (c) 2015, Iranian Red Crescent Medical Journal. This is an open-access article distributed under the terms of the Creative Commons Attribution-NonCommercial 4.0 International License (http://creativecommons.org/licenses/by-nc/4.0/) which permits copy and redistribute the material just in noncommercial usages, provided the original work is properly cited. 
running university for five consecutive years from 2006 to 2011. Moreover, this university has recently been categorized as one of the first ranked Iranian medical universities by the Iranian categorization of Medical schools.

\section{Objectives}

In this paper, we aimed to introduce the strategies employed by Baqiyatallah University of Medical Sciences of Iran, to enhance its scientific research output.

\section{Patients and Methods}

The present study used the qualitative content analysis technique. The Research deputies and the head of research centers of Baqiyatallah University of Medical Sciences, Tehran, Iran, were the research subjects. Documents and internal statistics were accessible, thanks to the working records of the deputy organization. The participants were all authorities of the university including the dean, ViceChancellor for Education, Vice-Chancellor for Research, and Head of all 14 research centers of the Baqiyatallah Research Council. We used the purposive sampling technique (expert sampling) in this study. Sampling was continued until data saturation. We planned to include the deputy of the chairmen if they were not able or willing to participate in the study. After speaking with 17 participants (age ranging between 40 to 55 years, with education level of at least MD or PhD and minimum of ten years work experience), the interviews yielded no new information, and no new categories or subcategories were added to the previous records. Deep and semi-structured interviews with open-ended questions were used to collect data. All experts cooperated and we did not have any excluded sample.

The main researcher conducted all the interviews. The interview (face-to-face) began with exchanging pleasantries with the aim of establishing a warm relationship with the participant. The interview continued with openended questions like; what did you do to improve your research knowledge? What do you think about the research ranking of the university? How many papers have you published in the recent years? What are the researches outcomes? Etc. Furthermore, all presented documents were recorded and coded as tape-recorded interviews.

For analyzing the data, conventional content analysis was used. This is mainly employed in studies aimed at describing a phenomenon, which has been briefly studied. In this approach, researchers usually avoid using predetermined categories. Instead, they allow the categories and their titles to be extracted. In the present study, the analysis of data involved three stages: encoding, recreating the categories and abstracting; as mentioned in the results. All information included a five-key stage; 1-familiarization, 2-identifying a thematic framework, 3-indexing, 4-charting, and 5-mapping and interpretation. We at first, wrote down all the information on coded papers (each paper related to each participant), and then the phenomenon was identified (as for our research, e.g. diplomacies, education, researches, etc.). Afterwards, all sub-phenomenon information was categorized and indexed and, the information was interpreted.

\subsection{Ethical Issues}

In our study, we considered all relevant ethical issues. We ensured that our field notes and transcripts did not contain personal identifiers. Furthermore, we kept all raw and processed data locked and/or password protected. We only shared data with those who were part of the study and who had received research ethics training. Furthermore, we conducted regular audits for the team, to ensure compliance.

\section{Results}

\subsection{Diplomacies Employed to Promote Research in Baqiyatallah University}

\subsubsection{Diplomacies Employed to Enhance Research En- deavors in Baqiyatallah University in 1998}

\subsubsection{Establishment of a Research Enhancement Asso- ciation}

To evaluate our university's research situation, primarily, we needed an expert panel to use ideas and set programs on this basis. Thus, an association was established between some of the most active faculty members of the university; their achievements are listed in Table 1 for discussion. Every member of the mentioned association was assigned to evaluate research activities of a number of faculty members of the university and to prepare a report.

\subsubsection{Evaluation of Weak Points of the Faculty and Rec- ognition of Those with Scientific Recession}

Members of the university's research association were given data of research activities of the faculty members, and then were asked to evaluate and point out those who did not have an improving trend for their research output, or those on a downward slope. Then the correspondent member of the association was asked to find the reason for the recession of the mentioned faculty member, and to suggest recommendations to solve the problem.

\subsubsection{Consultative Sessions for Faculty Members with Research Recession}

Next, a corresponding professor from the university research association was chosen for each of the faculty members with research recession, and each were asked to find and implement the best endeavors to improve their research activities. For this purpose, several consultative sessions were organized between faculty members to discuss their experiences and share their achievements. 
Saadat SH et al.

\begin{tabular}{|c|c|}
\hline $\begin{array}{l}\text { Year of evaluation in } \\
\text { Solar Hejra (Gregorian) }\end{array}$ & Achievements \\
\hline 1382 (March 2002-2003) & Second rank in student research committees among medical schools \\
\hline 1383 (March 2003-2004) & Third eminent researcher of the year \\
\hline 1384 (March 2004-2005) & First rank in medical research centers (by Research Center of Chemical Injuries) \\
\hline 1385 (March 2005-2006) & $\begin{array}{l}\text { Fourth rank in Research among Medical Universities; first rank in clinical research in internal medi- } \\
\text { cine (12th Rhazes Medical Research Festival); first rank in medical research centers (by Research Center } \\
\text { of Chemical Injuries) }\end{array}$ \\
\hline \multicolumn{2}{|l|}{1386 (March 2006-2007) } \\
\hline 1387 (March 2007-2008) & $\begin{array}{l}\text { Index university in research optimization in the country (14th Rhazes Medical Research Festival). } \\
\text { Achieving ranks from first to third amongst medical research centers of the country by the BRCGL, } \\
\text { Trauma Research Center and NURC, respectively }\end{array}$ \\
\hline 1388 (March 2008-2009) & $\begin{array}{c}\text { Third rank in best researcher in medicine and first rank in young investigator (15th Rhazes Medical } \\
\text { Research Festival) }\end{array}$ \\
\hline 1389 (March 2009-2010) & $\begin{array}{l}\text { Second rank in dentistry research, first rank in young investigator, first rank in research centers by } \\
\text { BRCGL (by 16th Rhazes Medical Research Festival) }\end{array}$ \\
\hline 1390 (March 2010-2011) & $\begin{array}{l}\text { First rank medical journal for Hepatitis Monthly, first rank research center and eminent student } \\
\text { researcher by the 17th Rhazes medical research festival. }\end{array}$ \\
\hline 1391 (March 2011-2012) & $\begin{array}{l}\text { First rank medical journal for Hepatitis Monthly with impact factor of } 2.19 \text {, eminent research center } \\
\text { by BRCGL, eminent young investigator, and second rank in research in internal medicine by the } 18 \text { th } \\
\text { Rhazes Medical Research Festival. }\end{array}$ \\
\hline
\end{tabular}

\subsection{Education}

\subsubsection{Organizing Educational Classes for the Faculty Members}

Once weaknesses and problems of faculty members were defined, it was time to solve these issues as much as possible to empower the faculty. For this purpose, educational classes were run to train the faculty members on different aspects of research. All these training endeavors were performed under the supervision and recommendations of correspondent professors from the university's research association.

\subsubsection{List of the Educational Classes}

Classes included methodology of medical research, performing and/or interpretation of statistical analyses, scientific writing (such as writing an abstract, introduction, methods and material, results, discussion, and conclusion sections), introduction for conducting clinical trials, randomization, double or triple blind trials, medical ethics, obtaining informed consent, obtaining ethical documentations from ethics committee, introduction to preparation of case reports, review articles, systematic reviews, etc.

\subsection{Foundation of Infrastructural Organizations for Research}

\subsubsection{Establishment of Research Centers and Laborato- rial Centers}

No doubt, research centers can induce a substantial impact on the improvement of research activities and output of universities and this improvement has the potential to go beyond statistics and enter the industry and make favorable changes in public health and economy (7). Moreover, research centers can serve as a place for gatherings of different members of the faculty to consult on their research endeavors, sharing their experiences, and performing inter-departmental researches and contributions. For all these purposes, and to be able to have centers that present measurable research output, and to correspond with other faculty members, we promoted and facilitated establishment of research centers at our university. Now, after 14 years, we have 16 research centers, amongst which "Research Center of Chemical Injuries" and "Research Center for Gastroenterology and Liver Disease" have become one of the most prestigious centers throughout the country.

\subsubsection{Developing High Level Education, and Granting} Subspecialties and PhD Degrees in Different Scientific Branches

One of the activities of our research centers was to enhance high-level education by absorbing and educating highly talented individuals. For this purpose, PhD courses have been established in 21 different branches of medical sciences at this university. Moreover, ten degrees of medical specialties, three subspecialties, and three fellowships are being granted by our university, and this list is expanding every year.

\subsubsection{Defining the Research Pathway for Each Center Based on Needs and Properties}

Due to almost unlimited pathways for research in front 
of each research center, and because of the shortage of either human or financial resources, we decided to determine some definite research pathways for each center, based on the country's needs.

\subsubsection{Contribution of Scientists from Basic and Clinical Sciences}

One of the most productive activities in medical sciences, which probably has the highest potential for scientific production in the economy and public health, is to link basic and clinical researches. For the same reason, contributions between research centers of basic sciences and those of clinical medicine have been highly promoted. However, we believe that the current situation is not a favorable one, and there is a long way ahead for improving and enhancing this cooperation.

\subsubsection{Announcing Priorities in Multi-central Researches}

After establishment of research centers and their enhancement to perform multi-central research, it was logical to receive a large number of proposals for research, whose financial needs were somewhat out of our budget. Thus, detection of research protocols with the highest priorities became inevitable. For this reason, committees of highly ranked scientists in the university were established and asked to control the budget and decide on the research priorities for granting funds.

\subsection{Surveillance and Rewards}

\subsubsection{Annual Granting of Research Output Documents for Each Faculty Member and Ranking}

After all the above-mentioned schedules, we needed a way to survey the faculty member's productivity and how much they followed the university's policies. For this purpose, at the end of each year, a research output document was granted to each faculty that provides them with their research activities, weaknesses and powers as well as recommendations for future endeavors. Moreover, each year, the faculty members were ranked based on their activities and output to provoke rivalry amongst them.

\subsubsection{Organizing Research Festivals and Rewarding the Forerunners}

Although evaluation of research endeavors of the faculty and notification of those with research recession are effective ways to enhance research output by the faculty, granting awards to those who had the greatest research activities can also endorse more efforts to increase research endeavors, which finally would enhance the situation of the university and the country. Thus, we planned to organize research festivals in which, we introduced and a rewarded faculty member with the highest research activities, which we believed, was a good way to bring competition between the faculty members and augment their output. One of the most attractive rewards we established was funding for participation in international congresses abroad.

\subsubsection{Establishment of the Students Research Commit- tee and Student Research Festivals}

Faculty members are undoubtedly the main resources of any university to promote research, and authorities must strongly focus on this human resource and improve their condition. However, students, despite their lower experience and skills, are also an invaluable resource for promoting research activities in the university. Students can help the faculty speed up their research and provide human resources needed to conduct and perform trials. Moreover, students can be considered as future members of the faculty, whose education and empowerment would be an invaluable investment for the future of the university and the country. For the same purpose, we established research committees for the students of our university to educate and include them in research trials, which not only improves the volume of researches performed in our university, but also educates a new generation of physicians with high research skills. To promote this purpose more profoundly, we also organized research festivals for the students to reward those with the highest research activities.

\subsubsection{Augmenting Activities and Correspondents to Ab- sorb Research Grants}

Encouraging faculty members and students to perform research is a very effective way to increase output, but without enough funds, research endeavors would soon reach a deadlock. To prevent this, we initiated extensive efforts to absorb research grants and cooperated with other research centers and universities with high levels of research funds.

\subsubsection{Granting Non-Profit Loans for Publications}

To provide funds for faculty members for their research endeavors, we proposed a non-profit loan to those aiming to publish books. We believe that this can help younger faculty members, who possess less financial resources, to promote their research activities further.

\subsubsection{Promoting the Establishment of Science-Based Companies}

Implementing research with attention to economy is perhaps the most effective way to enhance research. If a university and in a larger perspective, a country, could transfer research findings to productions and financial profit, it would provide not only funds for future research, but also, the highest levels of incentive for researchers and students. 


\section{Discussion}

Undoubtedly, the situation of any country in the world has a strong relationship with its condition in science production, and science production in any country has a direct association with the condition of its individual universities. On the other hand, it is a well-established fact that measurement of research output of faculty members of universities is a crucial endeavor in determining the contribution of staff to the overall research profile of the university (8).

Baqiyatallah University of Medical Sciences is a military university of limited resources that has won several awards in the recent years, and has been categorized as one of the leading among the first ranked medical universities in Iranian categorization of Medical schools. In this article, we described the plans and programs used by this university to gain these achievements.

Our study only exhibits the results of establishment of research plans in our university and we showed that at least the officials of the university are stating that these strategies can improve scientific ranking of medical universities. Nevertheless, we should note that there might be further information regarding new established plans for increasing the research output of a university, which, our subjects have not mentioned and therefore, we could not add them to our results such as grants outside of university, patents, international or regional collaborations, etc.

However, this article is based on narrative information, as we did not include information from other universi- ties in Iran. Furthermore, this report only includes information provided by education and research officials, and not the students nor the professors and other studies should be conducted regarding this issue.

\section{Acknowledgements}

The authors would like to gratefully acknowledge Dr. Zohreh Naderi, Dr. Belinda Gustavo, Mr. Fakhreddin Feizi, Mr. Taha Nasiri and Mr. Hossein Amini for their contribution in this research.

\section{References}

1. Jones J, Hunter D. Consensus methods for medical and health services research. BMJ. 1995;311(7001):376-80.

2. Pope C, Ziebland S, Mays N. Qualitative research in health care. Analysing qualitative data. BMJ.2000;320(7227):114-6.

3. Dobbins M, Ciliska D, Cockerill R, Barnsley J, DiCenso A. A framework for the dissemination and utilization of research for health-care policy and practice. Online J Knowl Synth Nurs. 2002;9:7.

4. Barlow DH. Health care policy, psychotherapy research, and the future of psychotherapy. Am Psychol. 1996;51(10):1050-8.

5. Braunwald E, Jones RH, Mark DB, Brown J, Brown L, Cheitlin MD, et al. Diagnosing and managing unstable angina. Agency for Health Care Policy and Research. Circulation. 1994;90(1):613-22.

6. Fairhurst K, Huby G. From trial data to practical knowledge: qualitative study of how general practitioners have accessed and used evidence about statin drugs in their management of hypercholesterolaemia. BMJ.1998;317(7166):1130-4.

7. Stahler GJ, Tash WR. Centers and institutes in the research university: issues, problems, and prospects. J High Edu. 1994:540-54.

8. Uzoka F. A fuzzy-enhanced multiincleria decision analysis model for evaluating university academics' research output. Info Knowl Syst Manag. 2008;7:273-299. 